\title{
Two acid sorbicillin analogues from saline lands-derived fungus Trichoderma sp.
}

\author{
Liying Ma, Weizhong Liu, Yuling Huang and Xianguo Rong
}

Two new acid sorbicillin analogues, (E)-6-(2,4-dihydroxyl-5-methylphenyl)-6-oxo-2-hexenoic acid (1) and 6-(2,4-dihydroxyl-5methylphenyl)-6-oxohexanoic acid (2), together with 12 known compounds, were isolated from a saline lands-derived fungus Trichoderma sp. The structures of the new compounds were established by interpretation of their spectroscopic data. Their cytotoxic effects on P388 and HL-60 cell lines were preliminarily evaluated by the 3-(4,5-dimethyl-2-thiazolyl)2,5-diphenyltetrazolium bromide (MTT) method. Furthermore, the new compounds exhibited weak radical scavenging activity against DPPH (1,1-diphenyl-2-picrylhydrazyl).

The Journal of Antibiotics (2011) 64, 645-647; doi:10.1038/ja.2011.54; published online 20 July 2011

Keywords: cytotoxicity; fungus; sorbicillinoids; Trichoderma sp.

\section{INTRODUCTION}

Fungi of the genus Trichoderma are ubiquitous in the environment. In recent years, more and more attention has been paid to them because of a wide range of prospective utility ${ }^{1}$ as biological control agents to suppress different fungal plant pathogens and to promote plant growth and for producing commercial enzymes, such as cellulases, hemicellulases, proteases and $\beta$-1,3-glucanase. ${ }^{2}$ At the same time, many structurally novel and biologically active secondary metabolites have been reported from the species. For example, peptibols, ${ }^{3}$ which are linear peptides characterized by an acetylated N-terminus, showed cytotoxic, membraneperturbing and antibiotic activities. Trichocaranes ${ }^{4} \mathrm{~A}-\mathrm{D}$, isolated from Trichoderma virens, significantly inhibited the growth of etiolated wheat coleoptiles. In addition, a series of sorbicillin-related compounds ${ }^{5-7}$ from Trichoderma showed moderate radical scavenging activity.

In our search for cytotoxic compounds from fungi, a Trichoderma sp. was isolated from the saline lands soil collected along the coast of Bohai Bay in Zhanhua, Shandong Province, China. Its extract showed moderate activity to brine shrimp. The isolation work led to the finding of two new compounds (E)-6-(2,4-dihydroxyl-5-methylphenyl)-6-oxo2-hexenoic acid (1) and 6-(2,4-dihydroxyl-5-methylphenyl)-6-oxohexanoic acid (2), along with 12 known ones, which were trichodimerol, bisvertinolone, adenosine, ergosterol, ergosterol peroxide, cerevisterol, $3 \beta, 5 \alpha$-dihydroxy- $6 \beta$-methoxyergosta-7,22-diene, $(22 E, 24 R)-5 \alpha, 6 \alpha$-epoxyergosta-8,22-diene-3 $\beta, 7 \alpha$-diol, cyclo-(L-prolyl-L-valine), cyclo-(L-leucyl-Lproline), cyclo-(L-isoleucyl-L-proline) and cyclo-(L-phenylalanyl-L-proline), respectively. The known compounds were identified by comparison with previously reported physical and spectral data. In this paper, we reported the new compounds' isolation, structure elucidation, cytotoxic activities to P388 and HL-60 cell lines and radical scavenging activity against DPPH (1,1-diphenyl-2-picrylhydrazyl) (Figure 1).

\section{RESULTS AND DISCUSSION}

Structure determination

Compound $\mathbf{1}$ was isolated as colorless needles. Its molecular formula was determined as $\mathrm{C}_{13} \mathrm{H}_{14} \mathrm{O}_{5}$ by high resolution electrospray ionization mass spectra. Its IR spectrum showed a broad absorption band for hydroxyl (about $3000 \mathrm{~cm}^{-1}$ ), characteristic absorptions for aromatic ring $\left(1604,1538\right.$ and $\left.1512 \mathrm{~cm}^{-1}\right)$ and carbonyl $\left(1668\right.$ and $\left.1628 \mathrm{~cm}^{-1}\right)$. The UV spectrum at 327 (3.89), 279 (4.12), 233 (4.02) and 211 (4.39) $\mathrm{nm}$, displayed typical absorptions of benzene ring connected with chromophore and auxochrome.

Analysis of the ${ }^{1} \mathrm{H}$ NMR data in conjunction with the HSQC spectrum disclosed the presence of one methyl, two aliphatic methylenes, two aromatic and two olefinic methines. The ${ }^{13} \mathrm{C}$ NMR spectrum further displayed the presence of one carboxyl, one ketone carbonyl and four aromatic quaternary carbons, two of which should be oxygenated in view of their chemical shifts $\left(\delta_{C} 164.63\right.$ and 164.58). The above evidence revealed the presence of a benzene ring with four substituents in 1, and two aromatic proton singlets strongly suggested that the two aromatic methine were in para positions. The upfield shift of the carboxyl carbon $\left(\delta_{\mathrm{C}}\right.$ 170.1) indicated conjugation with the double bond. In the HMBC spectrum, the correlations of $\mathrm{H}-12$ with $\mathrm{C}-13$ and C- 6 , and $\mathrm{H}-5$ with $\mathrm{C}-12$ demonstrated proximity of the methyl and the ketone carbonyl with the ortho aromatic carbon, C-12. The triplet of one aliphatic methylene proton signal $\left(\delta_{\mathrm{H}} 3.10\right)$ and the quartet of another $\left(\delta_{\mathrm{H}} 2.58\right)$ demonstrated the former linked with the carbonyl and the latter with an olefinic methine $\left(\delta_{\mathrm{H}} 6.98\right)$, which was observed a mutiplet. The E-geometry of the double bond was assigned on the basis of the coupling constant $(14.9 \mathrm{~Hz})$. The whole structure of $\mathbf{1}$ was confirmed by the HMBC spectrum (Figure 2).

Compound 2 was isolated as colorless needles. The high resolution electrospray ionization mass spectra indicated a molecular formula of 
<smiles>Cc1cc(C(=O)CCC=CC(=O)O)c(O)cc1O</smiles>

1

Figure 1 Structures of 1 and 2.

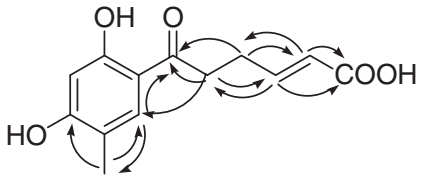

1<smiles>Cc1cc(C(=O)CCCCC(=O)O)c(O)cc1O</smiles>

2

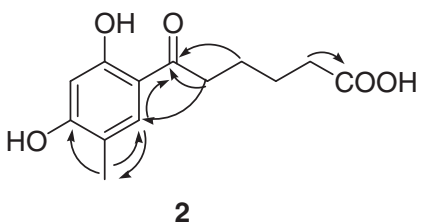

Figure $\mathbf{2}$ Key HMBC correlations for $\mathbf{1}$ and $\mathbf{2}$.

$\mathrm{C}_{13} \mathrm{H}_{16} \mathrm{O}_{5}$, which is 2 amu larger than $\mathbf{1}$; that is, a difference of $\mathrm{a}_{2}$ in the molecular formula. Its IR and UV spectra were almost the same as 1. Detailed analysis and comparison of the 1D NMR data, with those of 1, revealed the appearance of two additional aliphatic methylenes and the disappearance of two olefinic methines, which demonstrated that $\mathbf{2}$ is the hydrogenated derivative of $\mathbf{1}$. In addition, the disappearance of the double bond moved the chemical shift of the carboxyl downfield in 2 , which unambiguously confirmed the above conclusion. Finally, the HMBC data strongly supported the structure of 2 .

\section{Biological activities}

The cytotoxic effects of compounds 1 and $\mathbf{2}$ were preliminarily evaluated against P388 and HL-60 cell lines by the 3-(4,5-dimethyl2-thiazolyl)-2,5-diphenyltetrazolium bromide (MTT) method. The $\mathrm{IC}_{50}$ values of 1 and 2 against P388 and HL-60 cells were 72.8 and 44.5 , and 52.5 and $81.2 \mu \mathrm{M}$, respectively (fluorouracil as positive control, $\mathrm{IC}_{50} 3.8$ and $18.6 \mu \mathrm{m}$ against P388 and HL-60 cells, respectively). The results showed that they were slightly active against the two cell lines, and the double bond had little effect on the activity.

In addition, compounds $\mathbf{1}$ and $\mathbf{2}$ showed weak radical scavenging activity against $\mathrm{DPPH}$ with $\mathrm{IC}_{50}$ values of 175 and $142 \mu \mathrm{M}$, respectively (ascorbic acid as positive control, $\mathrm{IC}_{50} 21 \mu \mathrm{M}$ ).

These two new compounds belong to 'sorbicillinoids' in view of structure and likely biogenesis. 'Sorbicillinoids' and 'bisorbicillinoids' comprise a group of more than 30 monomeric and dimeric sorbicillin-related compounds, ${ }^{8}$ which exhibit a wide range of biological activities. To our best knowledge, this is the first time that acid analogues of 'sorbicillinoids' are reported. This discovery enrichs the range of this kind of compound and provides some materials for studies of structure-activity relationships.

\section{METHODS}

\section{General}

Melting points were measured on an XRC-1 micro-melting point apparatus (Sichuan University Scientific Instrument Factory, Chengdu, China) and were uncorrected. IR spectra were taken on a Nicolet 6700 spectrophotometer (Thermo Fisher Scientific, Madison, WI, USA) using attenuated total reflection method. UV spectra were recorded on Beckman DU 640 spectrophotometer (Global Medical Instrumentation, Inc., Ramsey, MN, USA). ESI-MS was measured on a Q-TOF Ultima GLOBAL GAA076 LC mass spectrometer (Waters Corporation, Milford, MA, USA). ${ }^{1} \mathrm{H},{ }^{13} \mathrm{C}$ NMR, DEPT, and 2D-NMR were recorded on a Bruker Avance 400 spectrometer (Bruker BioSpin AG,
Table $1{ }^{1} \mathrm{H}$ and ${ }^{13} \mathrm{C}$ NMR data for 1 and $2\left(\mathrm{MeOH}-d_{4}, 400\right.$ and $100 \mathrm{MHz}$, TMS, $\delta$ in p.p.m.)

\begin{tabular}{rrrrrr}
\hline & \multicolumn{2}{c}{1} & & \multicolumn{2}{c}{2} \\
\cline { 5 - 6 } \cline { 5 - 5 } No. & $\delta_{H}(\mathrm{~J}$ in Hz) & $\delta_{C}$ & & $\delta_{H}(\mathrm{~J} \mathrm{in} \mathrm{Hz})$ & $\delta_{C}$ \\
\hline \multirow{2}{nnnnyy}{1} & & $170.7 \mathrm{~s}$ & & $177.8 \mathrm{~s}$ \\
2 & $5.88(1 \mathrm{H}, \mathrm{d}, 14.9)$ & $123.9 \mathrm{~d}$ & $2.34(2 \mathrm{H}, \mathrm{t}, 6.5)$ & $35.1 \mathrm{t}$ \\
3 & $6.98(1 \mathrm{H}, \mathrm{m})$ & $148.9 \mathrm{~d}$ & $1.72(2 \mathrm{H}, \mathrm{m})$ & $25.5 \mathrm{t}$ \\
4 & $2.58(2 \mathrm{H}, \mathrm{q}, 6.9)$ & $27.7 \mathrm{t}$ & $1.72(2 \mathrm{H}, \mathrm{m})$ & $25.9 \mathrm{t}$ \\
5 & $3.10(2 \mathrm{H}, \mathrm{t}, 6.9)$ & $36.9 \mathrm{t}$ & $2.94(2 \mathrm{H}, \mathrm{t}, 6.9)$ & $38.3 \mathrm{t}$ \\
6 & & $204.2 \mathrm{~s}$ & & $206.0 \mathrm{~s}$ \\
7 & & $118.3 \mathrm{~s}$ & & $118.2 \mathrm{~s}$ \\
8 & & $164.6 \mathrm{~s}$ & & $164.7 \mathrm{~s}$ \\
9 & $6.25(1 \mathrm{H}, \mathrm{s})$ & $102.9 \mathrm{~d}$ & $6.24(1 \mathrm{H}, \mathrm{s})$ & $102.9 \mathrm{~d}$ \\
10 & & $164.6 \mathrm{~s}$ & & $164.5 \mathrm{~s}$ \\
11 & & $113.5 \mathrm{~s}$ & & $113.6 \mathrm{~s}$ \\
12 & $7.57(1 \mathrm{H}, \mathrm{s})$ & $133.2 \mathrm{~d}$ & $7.58(1 \mathrm{H}, \mathrm{s})$ & $133.4 \mathrm{~d}$ \\
13 & $2.11(3 \mathrm{H}, \mathrm{s})$ & $15.5 \mathrm{q}$ & $2.12(3 \mathrm{H}, \mathrm{s})$ & $15.5 \mathrm{q}$ \\
\hline
\end{tabular}

Fällanden, Switzerland) using tetramethylsilane (TMS) as internal standard. Semipreparative HPLC was performed on a SHIMADZU LC-6AD Liquid Chromatograph (SHIMADZU Corporation, Kyoto, Japan) with SPD-20A Detector (SHIMADZU Corporation), using an ODS column (HyperClone $5 \mu$ ODS $\left(\mathrm{C}_{18}\right) 120 \mathrm{~A}, 10 \times 250 \mathrm{~mm}$, Phenomenex, Torrance, CA, USA).

\section{Fungal material}

The working strain, Trichoderma sp JH8 (GenBank accession numbers: HQ717798), was isolated from the soil of saline lands collected along the coast of Bohai Bay in Zhanhua, Shandong Province, China. It was preserved in our laboratory. Working stocks were prepared on potato dextrose agar slants stored at $4{ }^{\circ} \mathrm{C}$.

\section{Fermentation, extraction and isolation}

Spores growing on petri dishes of potato dextrose agar were inoculated into 500-ml Erlenmeyer flasks containing $180 \mathrm{ml}$ sea water-based culture medium (potato $200 \mathrm{~g}$, glucose $20 \mathrm{~g}$, mannitol $10 \mathrm{~g}$, maltose $10 \mathrm{~g}$, yeast extract $3 \mathrm{~g}$, $\mathrm{KH}_{2} \mathrm{PO}_{4} 0.5 \mathrm{~g}, \mathrm{MgSO}_{4} \cdot 7 \mathrm{H}_{2} \mathrm{O} 0.3 \mathrm{~g}$, dissolved in 11 seawater), and cultured at $28^{\circ} \mathrm{C}$ for 8 days on a rotary shaker at 170 r.p.m.

The culture broth (50l) was filtered through cheesecloth to separate the mycelia. The filtrate was extracted three times with ethyl acetate, whereas the mycelia were extracted three times with methanol. The methanol solution was evaporated under reduced pressure to afford an aqueous solution, which was extracted three times with ethyl acetate. The ethyl acetate extracts were combined and concentrated in vacuo to give a crude extract (56g).

The crude extract was subjected to silica gel (200-300 mesh) column chromatography, eluting with a step gradient of petroleum ether-chloroform and chloroform-methanol mixtures. The fraction that was obtained with chloroform-methanol (40:1) was rechromatographed on a column of reverse phase silica gel (RP18, $25 \sim 40 \mu \mathrm{m}$, Merck KGeA, Darmstadt, Germany) with an $\mathrm{H}_{2} \mathrm{O} / \mathrm{MeOH}$ gradient. The subfraction obtained from $\mathrm{H}_{2} \mathrm{O} / \mathrm{MeOH}(8: 1)$ was further separated by semipreparative HPLC on an ODS column (Phenomenex), using methanol-water (2:3) as eluting solvent to yield compounds $1(25 \mathrm{mg})$ and $2(36 \mathrm{mg})$.

\section{Biological assay}

The cell lines were grown in RPMI-1640 supplemented with $10 \%$ fetal bovine serum under a humidified atmosphere of $5 \% \mathrm{CO}_{2}$ and $95 \%$ air at $37^{\circ} \mathrm{C}$. Cell suspensions, $200 \mu \mathrm{l}$, at a density of $5 \times 10^{4} \mathrm{cell} \mathrm{ml}^{-1}$ were plated in 96 -well microtiter plates and incubated for $24 \mathrm{~h}$ under the above conditions. Then $2 \mu \mathrm{l}$ portions of the test compound solutions at different concentrations in $\mathrm{MeOH}$ were added to each well, and incubation continued for $72 \mathrm{~h}$ under the same conditions. Finally, $20 \mu \mathrm{l}$ of MTT solution $\left(5.0 \mathrm{mg} \mathrm{ml}^{-1}\right.$ in RPMI-1640 
medium) was added to each well and incubation continued for $4 \mathrm{~h}$. Then, the medium containing MTT, $150 \mu \mathrm{l}$, was removed from each well and gently replaced by dimethyl sulfoxide to dissolve any formazan crystals that formed. Absorbance was then determined on SPECTRAMAX PLUS plate reader (Molecular Devices Corporation, Sunnyvale, CA, USA) at $540 \mathrm{~nm}$. The $\mathrm{IC}_{50}$ values were obtained using the Bliss method.

In the DPPH scavenging assay, the samples to be tested were dissolved in methanol and the solution $(160 \mu \mathrm{l})$ was dispensed into wells of a 96-well microtiter tray. DPPH solution in methanol $\left(3.0 \times 10^{-4} \mathrm{moll}^{-1}\right), 40 \mu \mathrm{l}$, was added to each well. After thorough mixing, the mixture was kept in the dark for $30 \mathrm{~min}$. Thereafter, the absorbance was measured at $517 \mathrm{~nm}$ using methanol as the blank reference, and the percent inhibition was calculated. $\mathrm{IC}_{50}$ values denote the concentration of sample required to scavenge $50 \%$ of the DPPH free radicals.

\section{Physico-chemical properties}

Compound 1: colorless needle $(\mathrm{MeOH}) ; \mathrm{mp} 220 \sim 222^{\circ} \mathrm{C}$; high resolution electrospray ionization mass spectra $\mathrm{m} / \mathrm{z} 249.0767$ for $[\mathrm{M}-\mathrm{H}]^{-}$(calcd for $\mathrm{C}_{13} \mathrm{H}_{13} \mathrm{O}_{5}, 249.0763$ ); IR (attenuated total reflection) $v_{\max } \mathrm{cm}^{-1} 3500 \sim 2800$, $1668,1628,1604,1539,1512,1464,1381,1267,1227,1183,1142,1003,966$, 882, 858, 842, 794, 767, 747, 711; UV-vis (MeOH) $\lambda_{\max } \mathrm{nm}(\log \varepsilon) 327$ (3.89), 279 (4.12), 233 (4.02), 211 (4.39); ${ }^{1} \mathrm{H}$ and ${ }^{13} \mathrm{C}$ NMR see Table 1.

Compound 2: colorless needle $(\mathrm{MeOH}) ; \mathrm{mp} 210 \sim 212^{\circ} \mathrm{C}$; high resolution electrospray ionization mass spectra $\mathrm{m} / \mathrm{z} 251.0908$ for $[\mathrm{M}-\mathrm{H}]^{-}$(calcd for $\mathrm{C}_{13} \mathrm{H}_{15} \mathrm{O}_{5}$ 251.0919); IR (attenuated total reflection) $v_{\max } \mathrm{cm}^{-1} 3390 \sim 2800$, $1633,1591,1513,1462,1416,1378,1316,1278,1204,1183,1151,1004,973$, 931, 919, 887, 844, 813, 744, 690; UV-vis $(\mathrm{MeOH}) \lambda_{\max } \mathrm{nm}(\log \varepsilon) 326$ (3.82), 278 (4.05), 234 (3.94), 213 (4.16); ${ }^{1} \mathrm{H}$ and ${ }^{13} \mathrm{C}$ NMR see Table 1.

\section{ACKNOWLEDGEMENTS}

This work was financially supported by the Natural Science Foundation of Shandong Province, China (No.Y2008B17). The working strain, Trichoderma sp JH8, was identified by Dr Tianjiao Zhu (Key Laboratory of Marine Drugs, Chinese Ministry of Education, School of Medicine and Pharmacy, Ocean University of China.). We appreciate Professor Qianqun Gu, Ocean University of China, for HRESIMS measurements and beneficial discussion.

1 Verma, M., Brar, S. K., Tyagi, R. D., Surampalli, R. Y. \& Valero, J. R. Antagonistic fungi, Trichoderma spp.: Panoply of biological control Biochem. Eng. J. 37, 1-20 (2007)

2 Montero, M., Sanz, L., Rey, M., Monte, E. \& Llobell, A. BGN16.3, a novel acidic $\beta-1,6$ glucanase from mycoparasitic fungus Trichoderma harzianum CECT 2413. FEBS $J$ 272, 3441-3448 (2005)

3 Ruiz, N. et al. New Trichobrachins, 11-residue peptaibols from a marine strain of Trichoderma longibrachiatum. Peptides 28, 1351-1358 (2007)

4 Macias, F. A. et al. Bioactive carotanes from Trichoderma virens. J. Nat. Prod. 63, 1197-1200 (2000)

5 Abe, N., Sugimoto, O., Hirota, A. \& Murata, T. Novel DPPH radical scavengers, bisorbicillinol and demethyltrichodimerol, from a fungus. Biosci. Biotechnol. Biochem. 62, 661-666 (1998).

6 Abe, N., Murata, T. \& Hirota, A. Novel oxidized sorbicillin dimmers with 1,1-diphenyl-2picryldrazyl-radical scavenging activity from a fungus. Biosci. Biotechnol. Biochem. 62, 2120-2126 (1998).

7 Abe, N., Yamamoto, K. \& Hirota, A. Novel fungal metabolites, demethylsorbicillin and oxosorbicillinol, isolated from Trichoderma sp. USF-2690. Biosci. Biotechnol. Biochem. 64, 620-622 (2000).

$8 \mathrm{Du}$, L. et al. Cytotoxic sorbicillinoids and bisorbicillinoids from a marine-derived fungus Trichoderma sp. Chem. Pharm. Bull. 57, 220-223 (2009). 